\title{
Are there clinical factors that can predict prolonged survival of patients receiving olaparib as maintenance therapy for BRCA-mutated ovarian cancer?
}

\author{
Howard B. Lieberman ${ }^{1,2}$ \\ ${ }^{1}$ Center for Radiological Research, Columbia University Vagelos College of Physicians and Surgeons, New York, NY, USA; ${ }^{2}$ Department of \\ Environmental Health Sciences, Columbia University Mailman School of Public Health, New York, NY, USA \\ Correspondence to: Howard B. Lieberman. Center for Radiological Research, Columbia University Vagelos College of Physicians and Surgeons, 630 W. \\ 168th St., New York, NY 10032, USA. Email: HBL1@cumc.columbia.edu. \\ Comment on: Labidi-Galy SI, de La Motte Rouge T, Derbel O, et al. Clinical factors associated with prolonged response and survival under olaparib \\ as maintenance therapy in BRCA mutated ovarian cancers. Gynecol Oncol 2019;155:262-9.
}

Submitted Dec 16, 2019. Accepted for publication Dec 30, 2019.

doi: $10.21037 /$ tcr.2019.12.102

View this article at: http://dx.doi.org/10.21037/tcr.2019.12.102

Ovarian cancer is highly prevalent and the second most deadly gynecological cancer (1). It is estimated that globally in the year 2018 there were 295,414 new cases and 184,799 deaths because of this disease. Epithelial ovarian carcinomas account for $85 \%$ to $90 \%$ of all malignant ovarian cancers, and more than half of those are the histotype serous carcinoma (2). Furthermore, the median age of women diagnosed with this disease is about 60 65 years old (3). Typically, the initial stages of ovarian cancer are asymptomatic, and thus early detection is difficult and only occurs for about $20 \%$ of newly diagnosed patients (4). Nevertheless, when detected at an early stage, $94 \%$ of patients can live more than 5 years after initial diagnosis (5).

Treatment options for patients with ovarian cancer depend upon the type and stage of the disease, as well as special circumstances that could impact therapeutic efficacy. Localized treatment usually includes debulking surgery or more rarely radiotherapy. For systemic treatment, chemotherapy, hormone therapy, or an ovarian cancer targeted approach is employed.

The genetic makeup of ovarian cancer has been exploited to design and explain the mechanistic basis for effective precision treatments. BRCA1 and BRACA2 are tumor suppressors that participate in repair of DNA damage, such as double stand breaks, through homologous recombination. Germline and somatic mutations in one or both of the genes are present in greater than $25 \%$ of high-grade serous carcinomas (6). Since homologous recombination can repair double strand DNA breaks caused by such drugs as platinum, the favorable response of ovarian cancer patients bearing $B R C A 1$ or $B R C A 2$ mutation, and thus deficiency in this repair process, to this treatment is predictable. Other proteins and pathways can also repair damage caused by platinum. For example, Poly(ADP-ribose) polymerase 1 (PARP1) plays numerous roles that impact repair of DNA damage, functioning in single-strand break repair, nucleotide excision repair, double-strand break repair, the stabilization of replication forks, and modulating chromatin structure, as well as in homologous recombination repair (7). A genetically engineered mouse model was used to demonstrate that BRCA1-deficiency sensitizes mammary tumors to the PARP1 inhibitor olaparib, alone as well as in combination with platinum drugs (8). Based on the synthetic lethal effects caused by blocking alternative pathways that impact DNA repair, platinum-based chemotherapy is used in combination with PARP inhibitors to treat ovarian cancer patients with inherent deficiencies in homologous recombination due to BRCA1 and BRCA2 mutation (9).

Labidi-Galy et al. (10) reported the results of a multicenter retrospective, 115 patient cohort study to assess the benefit of using the PARP1, PARP2, and PARP3 inhibitor olaparib as maintenance therapy for patients with epithelial ovarian cancer bearing germline or somatic mutation in $B R C A 1$ or $B R C A 2$. Of the patients examined, $95 \%$ had germline mutations (including one patient with a $B R C A 1$ and BRCA2 mutation), and only 6 had somatic mutations, 
all in BRCA1. Data from the single patient with the double $B R C A 1 / B R C A 2$ mutation were evaluated separately. The study demonstrates three factors that predict prolonged response and survival to olaparib when used as maintenance therapy. Patients with a platinum-free interval longer than 12 months, radiological indication of a partial or complete response, and normalization of marker CA-125 levels before olaparib treatment provided expectation of the best response. Interestingly, these investigators noted that a subset of the relapsing cohort had limited benefit from olaparib treatment alone. They cited studies reporting that $B R C A$ mutated epithelial ovarian cancers had high quantities of infiltrating lymphocytes $(11,12)$, as well as express PD-1 and PD-L1 (13). They speculate that this subset of patients might benefit by the combination of PARP inhibitor and anti-PD-1/PD-L1 treatment, which is backed up by preclinical mouse studies focused on anti-PD-1 (14). They cite two ongoing clinical trials, and there are others testing the efficacy of combined PARP inhibitor and anti-PD-1/PD-L1 immune checkpoint blocking treatments (NCT02484404, NCT02571725, NCT02657889, NCT02734004).

There is clearly increased interest in tailoring cancer treatment to individuals based on the genetic makeup of tumors and status of disease, using a precision medicine approach. The study by Labidi-Galy and co-workers (10) is an example of this strategy and provides information to aid in determining the subset of ovarian cancer patients who would benefit most from olaparib maintenance treatment. Future studies could focus on stratifying patients for predicted treatment response, based on exact BRCA1/ $B R C A 2$ mutation, or degree of homologous recombination deficiency. It would also be important to evaluate different PARP inhibitors, such as olaparib (AZD2281 \#A10111), rucaparib (AG014699 \#A10045) and niraparib (MK4827 \#A11026), for efficacy in this treatment scenario.

\section{Acknowledgments}

Funding: None.

\section{Footnote}

Provenance and Peer Review: This article was commissioned by the editorial office, Translational Cancer Research. The article did not undergo external peer review.

Conflicts of Interest: The author has completed the ICMJE uniform disclosure form (available at http://dx.doi. org/10.21037/ tcr.2019.12.102). The author has no conflicts of interest to declare.

Ethical Statement: The author is accountable for all aspects of the work in ensuring that questions related to the accuracy or integrity of any part of the work are appropriately investigated and resolved.

Open Access Statement: This is an Open Access article distributed in accordance with the Creative Commons Attribution-NonCommercial-NoDerivs 4.0 International License (CC BY-NC-ND 4.0), which permits the noncommercial replication and distribution of the article with the strict proviso that no changes or edits are made and the original work is properly cited (including links to both the formal publication through the relevant DOI and the license). See: https://creativecommons.org/licenses/by-nc$\mathrm{nd} / 4.0 \%$.

\section{References}

1. Bray F, Ferlay J, Soerjomataram I, et al. Global cancer statistics 2018: GLOBOCAN estimates of incidence and mortality worldwide for 36 cancers in 185 countries. CA Cancer J Clin 2018;68:394-424.

2. Berek JS, Bast RC, Epithelial Ovarian Cancer. In: Holland-Frei Cancer Medicine, 6th edition. Kufe DW, Pollock RE, Weichselbaum RR, et al., editors. Hamilton $(\mathrm{ON})$ : BC Decker, 2003.

3. Scully RE, Young RH, Clement PB. Tumors of the ovary, maldeveloped gonads, fallopian tube, and broad ligament. Third Series, Fascicle 23. Washington, DC: Armed Forces Institute of Pathology, 1998.

4. Das PM, Bast RC Jr. Early detection of ovarian cancer. Biomark Med 2008;2:291-303.

5. Berek JS, Friedlander ML, Hacker NF. Chapter 11: Epithelial Ovarian, Fallopian Tube, and Peritoneal Cancer. In: Berek \& Hacker's Gynecologic Oncology, 6th edition. Philadelphia: Wolters Kluwer Health, 2015.

6. Manchana T, Phoolcharoen N, Tantbirojn P. BRCA mutation in high grade epithelial ovarian cancers. Gynecol Oncol Rep 2019;29:102-5.

7. Ray Chaudhuri A, Nussenzweig A. The multifaceted roles of PARP1 in DNA repair and chromatin remodelling. Nat Rev Mol Cell Biol 2017;18:610-21.

8. Rottenberg S, Jaspers JE, Kersbergen A, et al. High sensitivity of BRCA1-deficient mammary tumors to the PARP inhibitor AZD2281 alone and in combination 
with platinum drugs. Proc Natl Acad Sci U S A 2008;105:17079-84.

9. Mateo J, Lord CJ, Serra V, et al. A decade of clinical development of PARP inhibitors in perspective. Ann Oncol 2019;30:1437-47.

10. Labidi-Galy SI, de La Motte Rouge T, Derbel O, et al. Clinical factors associated with prolonged response and survival under olaparib as maintenance therapy in BRCA mutated ovarian cancers. Gynecol Oncol 2019;155:262-9.

11. McAlpine JN, Porter H, Köbel M, et al. BRCA1 and BRCA2 mutations correlate with TP53 abnormalities and presence of immune cell infiltrates in ovarian high-grade serous carcinoma. Mod Pathol 2012;25:740-50.

Cite this article as: Lieberman HB. Are there clinical factors that can predict prolonged survival of patients receiving olaparib as maintenance therapy for $B R C A$-mutated ovarian cancer? Transl Cancer Res 2020;9(2):418-420. doi: 10.21037/ tcr.2019.12.102
12. Goodman MT, Shvetsov YB. Incidence of ovarian, peritoneal, and fallopian tube carcinomas in the United States, 1995-2004. Cancer Epidemiol Biomarkers Prev 2009;18:132-9.

13. Strickland KC, Howitt BE, Shukla SA, et al. Association and prognostic significance of BRCA1/2-mutation status with neoantigen load, number of tumor-infiltrating lymphocytes and expression of PD-1/PD-L1 in high grade serous ovarian cancer. Oncotarget 2016;7:13587-98.

14. Ding L, Kim HJ, Wang Q, et al. PARP Inhibition Elicits STING-Dependent Antitumor Immunity in Brca1Deficient Ovarian Cancer. Cell Rep 2018;25:2972-80.e5. 